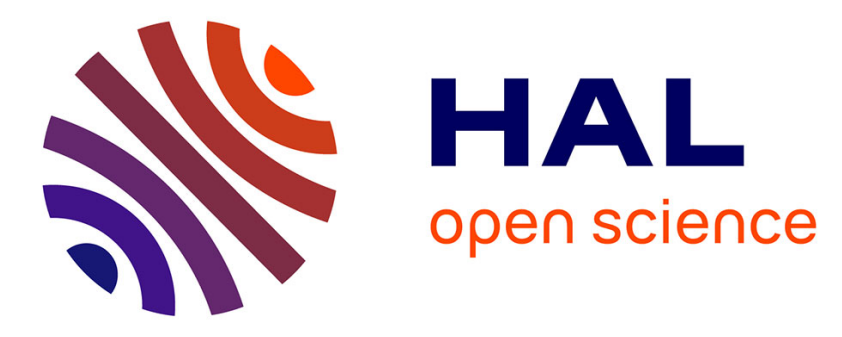

\title{
Mid-infrared absorption properties of green wood
}

Anna Dupleix, Domingos de Sousa Meneses, Mark Hughes, Rémy Marchal

\section{To cite this version:}

Anna Dupleix, Domingos de Sousa Meneses, Mark Hughes, Rémy Marchal. Mid-infrared absorption properties of green wood. Mid-infrared absorption properties of green wood, 2013, pp.1-13. hal00844551

\section{HAL Id: hal-00844551 \\ https://hal.science/hal-00844551}

Submitted on 15 Jul 2014

HAL is a multi-disciplinary open access archive for the deposit and dissemination of scientific research documents, whether they are published or not. The documents may come from teaching and research institutions in France or abroad, or from public or private research centers.
L'archive ouverte pluridisciplinaire HAL, est destinée au dépôt et à la diffusion de documents scientifiques de niveau recherche, publiés ou non, émanant des établissements d'enseignement et de recherche français ou étrangers, des laboratoires publics ou privés. 


\title{
Mid-infrared absorption properties of green wood
}

\author{
Anna Dupleix • Domingos De Sousa Meneses • \\ Mark Hughes • Rémy Marchal
}

\begin{abstract}
There is a lack of quantitative data on the penetration depth and the amount of energy absorbed by green wood under infrared (IR) radiation. This lack of knowledge is a potential barrier to the development of IR heating as an alternative to soaking as a means of warming logs prior to peeling in the manufacture of plywood. Experimental measurements of normal hemispherical spectral reflectance and transmittance over the range $550-5,500 \mathrm{~cm}^{-1}$ wavenumbers on four wood species, beech, birch, Douglas-fir and spruce have brought new knowledge on mid-infrared absorption properties of green wood and removed some uncertainties. For instance, it is not possible to deliver energy deeper than up to $0.3 \mathrm{~mm}$ below the wood surface because 70-90 \% of all incident IR radiation on the wood surface is absorbed in this layer. Some wood features, such as surface quality, the presence of knots and of free water in wood (the latter two having a more significant effect) influence the amount of energy absorbed. These results illustrate that IR radiation can heat the surface layers, but then heat penetrates deeper into the inside layers of wood by conduction.
\end{abstract}

\section{Introduction}

The objective of the study reported herein was to determine the optical properties of green wood and wood at moisture contents below this level under infrared (IR)

\author{
A. Dupleix $(\bowtie) \cdot$ R. Marchal \\ Arts et Metiers ParisTech LaBoMaP, Rue Porte de Paris, 71250 Cluny, France \\ e-mail: anna.dupleix@ensam.eu \\ A. Dupleix · M. Hughes \\ Department of Forest Products Technology, School of Chemical Technology, Aalto University, \\ 00076 Aalto, Finland \\ D. De Sousa Meneses \\ Conditions Extrêmes et Matériaux: Haute Température et Irradiation (CEMHTI), UPR 3079, 1D \\ Avenue de la Recherche Scientifique, 45071 Orleans Cedex 2, France
}


radiation. Characterisation involved the experimental measurement of diffuse reflectance and transmittance IR spectra. From these results, it was possible to estimate the amount of energy absorbed by the wood and the penetration depth of the IR radiation. This work provides a better understanding of the interaction between wood and IR radiation and gives insight into the technical feasibility of heating green wood using IR radiation. Furthermore, the new knowledge acquired here could be used to improve the accuracy of numerical models designed to simulate the thermal behaviour of wood whilst being heated by an external IR source (Dupleix et al. 2013a). This work is part of a wider project investigating the ability to heat green wood with IR radiation as an alternative technology to soaking prior to peeling.

The heating of logs prior to peeling to increase the deformability of green wood under the cutting knife is a key stage in the manufacture of veneer. This 'softening' of the wood has traditionally been carried out on an industrial scale by soaking the logs in hot water. This softening of the wood benefits the peeling process by lowering the cutting forces (Marchal et al. 2004) and improving veneer quality by reducing the risk of checking (Dupleix et al. 2013b). Ideally, the heating temperature should exceed the glass transition temperature, $\mathrm{Tg}$, of the native hemicelluloses-lignin matrix, which in turn is dominated by the Tg of lignin at the moisture content of green wood (Engelund et al. 2013) and differs from the Tg of the isolated wood polymeric constituents (Navi and Sandberg 2012).

The long soaking times (from 24 to $48 \mathrm{~h}$ ) needed to soften the log throughout points towards the need for a more rapid method of log heating. Feasibly, this might be achieved by embedding a heating system directly onto the peeling lathe to heat the bolt whilst peeling it. For this, it would be necessary to have a system that heats green wood very rapidly in order to cope with the high peeling rates demanded by industry (from 1 to $10 \mathrm{~m} / \mathrm{s}$ ). The thermal conductivity of wood remains low even at green wood moisture contents (Dupleix et al. 2013c) suggesting that the feasibility of IR heating of green wood whilst peeling depends upon the ability of green wood to absorb radiation from IR exposure and on the efficacy of heat transfer into green wood by radiation rather than by conduction.

Early work on oak reported that IR radiation is 'intensively' absorbed by the surface (Grimhall and Hoel 1983). The rate of IR absorption was determined from the temperature profile within the wood: the increase in temperature deep in the wood was assumed to be an indirect measure of the penetration depth of the IR radiation. Similar measurements applied to oak at moisture contents of between 0 and $20 \%$ suggested that in all probability, the penetration depth of IR was less than $0.1 \mathrm{~mm}$ (Makoviny and Zemiar 2004). However, with this method, it remains difficult to precisely evaluate heat absorption into wood by radiation because the measurement techniques are necessarily biased by heat transfer through conduction (Cserta et al. 2012). Recent developments in IR spectroscopy have yielded more precise estimates of IR penetration into wood. The penetration depth has been calculated to range from 0.13 to $2.15 \mu \mathrm{m}$ depending upon the wavelength (Zavarin et al. 1991) with a maximum depth of penetration of $37-138 \mu \mathrm{m}$ recorded at $2,242 \mathrm{~cm}^{-1}$, decreasing with wood density (Zavarin et al. 1990). From the forgoing studies by Zavarin et al. (1990, 1991), there is some controversy about the effect of 
surface roughness on absorbance and it has also been reported to differ according to wavelength (Tsuchikawa et al. 1996). However, all these results originated from dry wood, and data on the penetration depth into green wood are lacking. The only study on the effect of moisture content on the optical properties of wood refers to emissivity. Kollmann and Côté (1968) reported that wet wood absorbs more IR energy than dry wood and that wood emissivity increases with MC up to fibre saturation point (fsp), at which point the emissivity of wood is the same as that of water $(\varepsilon=0.93)$. Emissivity values provided by the manufacturers of IR thermography cameras (e.g. FLIR System 2004) are given for all wavelengths of incident IR radiation, and the wood moisture content (MC) is referred to as either 'dry' or 'damp' which is not precise enough to obtain a clear picture of the dependence of optical properties on moisture content. Some experimental work has investigated the transmission and absorption of wet Douglas-fir, beech and oak veneers in the near- and mid-infrared range using a flux meter located underneath the exposed veneer (Marchal et al. 2004). From this work, it was concluded that veneers of between 0.5 and $2 \mathrm{~mm}$ absorb around $50 \%$ and transmit around $10 \%$ of the incident flux. These values were constant irrespective of the source wavelength, and transmission was found to increase with increasing MC but decrease with sample thickness. However, it is believed that these results should be considered with care because the flux meter may have been influenced by extraneous ambient light.

This paper reports the spectra of normal hemispherical spectral reflectance and transmittance over the wavenumber range $550-5,500 \mathrm{~cm}^{-1}$, i.e., from 18 to $1.8 \mu \mathrm{m}$ wavelengths, in four wood species: beech (Fagus sylvatica), birch (Betula pendula), Douglas-fir (Pseudotsuga menziesii) and spruce (Picea abies) and from ambient MC (around $12 \%$ ) to the saturated state. Conclusions about the absorption of IR radiation by wood at various moisture contents are drawn.

\section{Materials and methods}

\section{Samples}

Locally sourced bolts of beech, birch, Douglas-fir and spruce were peeled on a lathe at $1.5 \mathrm{~m} / \mathrm{s}$ without prior soaking. Samples were cut from the veneers in the form of 30-mm diameter discs using a circular cutter. Sample thicknesses varied from 0.2 to $3.1 \mathrm{~mm}(0.2,0.3,0.5,0.7,0.9,1.1,1.2,1.6,2.0,2.1,2.2,2.3,3.0$ and $3.1 \mathrm{~mm})$. Green samples that had never been dried were kept wrapped in plastic bags just after peeling to prevent moisture loss. Other samples of veneer, air-dried at ambient temperature, were soaked in cold water to moisten them. The aim of using both green veneer and moistened veneer was to investigate possible differences in the optical properties arising from structural difference in the veneer caused by initial drying, since it is known that hornification takes place on initial drying. MC was determined gravimetrically where the initial weight was the weight measured just after the experiments (Eq. 1). The oven-dry weight was obtained after the samples had been dried in an oven maintained at a temperature 
of $103{ }^{\circ} \mathrm{C}$ for around $24 \mathrm{~h}$ and until the mass loss during a 3-h interval was less than $0.02 \mathrm{~g}$ (ASTM 2002).

$$
M C(\%)=\frac{\text { initial weight }(\mathrm{g})-\text { ovendry weight }(\mathrm{g})}{\text { ovendry weight }(\mathrm{g})}
$$

Limiting the time of measurement to a couple of seconds minimised the risk of drying during the experiments. Moreover, as a precaution, the samples were carefully enfolded in plastic bags between each measurement in order to avoid any moisture loss, and the sample MC was determined before and after each measurement to ensure that no moisture loss had occurred. Negligible MC differences, never exceeding $1 \%$, were recorded in this process.

Integrating sphere device

Optical properties were measured with an integrating sphere device providing reflectance and transmittance spectra. This device consists of a Bruker Vertex 70 spectrometer equipped with a 6-inch integrating sphere (Hoffman SphereOptics) with a diffuse reflective gold coating. Single channel signals were acquired with a resolution of $4 \mathrm{~cm}^{-1}$ using an instrumental configuration composed of a globar source, a $\mathrm{Ge} / \mathrm{KBr}$ beamsplitter and a nitrogen liquid cooled MCT (Mercury Cadmium Telluride $\mathrm{HgCdTe}$ ) photoconductive infrared detector. Normal hemispherical reflectance $R$ and transmittance $T$ were calculated from different spectra (Eqs. 2 and 3). In order to suppress any parasitic contribution appearing in reflectance mode, the reflectance spectra $R$ were background corrected with a measure of the ambient spectra (spectra A in Fig. 1a). Reference spectra $M$ were acquired with a mirror used as a gold diffuse reference (Fig. 1b). Spectra $E_{\mathrm{R}}$ and $E_{\mathrm{T}}$ were obtained by using the adequate integrating sphere configurations described in Fig. 1c, d, respectively.

$$
\begin{gathered}
R=\frac{E_{\mathrm{R}}-A}{M-A} \\
T=\frac{E_{\mathrm{T}}}{M}
\end{gathered}
$$

\section{Method}

Normal hemispherical reflectance spectra give, for each wavelength of the incident radiation, the amount of energy which leaves the incident sample surface without being absorbed because of reflectivity at the air-material interface or backward scattering by the wood fibres. Normal hemispherical transmittance spectra give, for each wavelength of the incident radiation, the amount of energy transmitted through the sample.

A simple energy balance shows that the amount of energy $A$ absorbed by the material is given by Eq. 4 . 
(a) Configuration of spectra $\mathrm{A}$

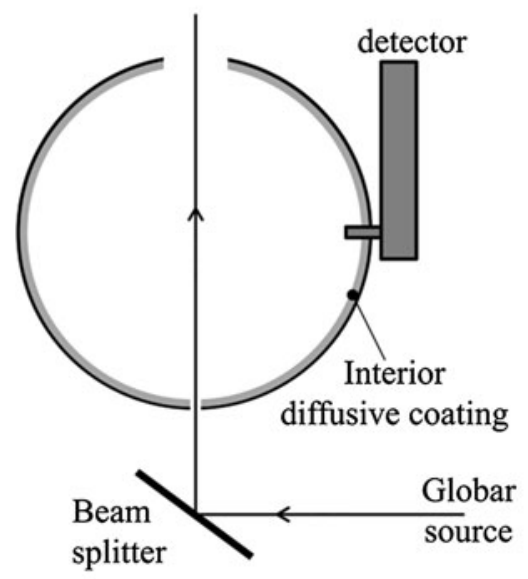

(c) Configuration of spectra $E_{R}$

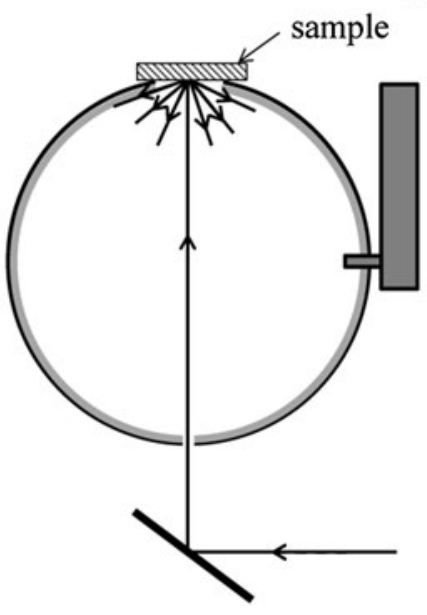

(b) Configuration of spectra $\mathrm{M}$

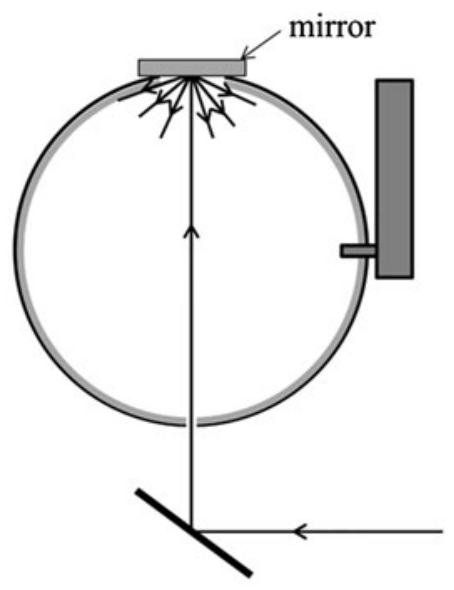

(d) Configuration of spectra $\mathrm{E}_{\mathrm{T}}$

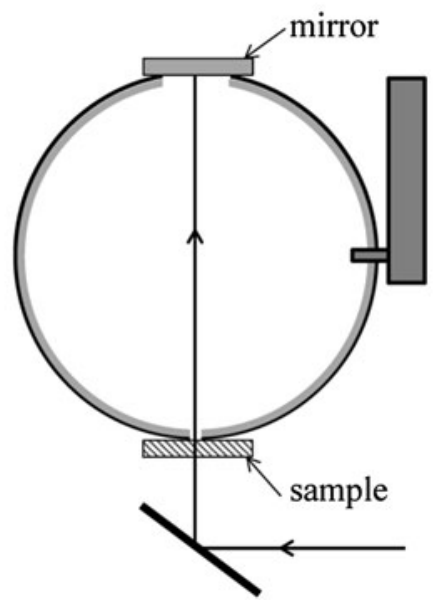

Fig. 1 Scheme of the different configurations of the integrating sphere to obtain a spectra A, b spectra M, c spectra $E_{\mathrm{R}}$ and $\mathbf{d}$ spectra $E_{\mathrm{T}}$

$$
A=1-R-T
$$

where $A=$ absorptivity, $R=$ reflectivity, $T=$ transmissivity.

Due to their heterogeneous structures (porosity, fibres, etc.), light scattering is strong inside wood. So the penetration depths of these samples cannot be simply defined by the inverse of the absorption coefficient. Rather, a qualitative penetration depth is estimated by testing samples of decreasing thicknesses. As long as transmission is nearly equal to zero-meaning that all incident radiation is absorbed or reflected by the sample-the penetration depth is known to be less than the sample thickness. In other words, the penetration depth reported in this paper is given by the thinnest veneer section which gives a non-zero value for transmission. 


\section{Results and discussion}

In Figs. 2, 3, 4, 5, 6, the small peak at around 2,400 $\mathrm{cm}^{-1}$ (marked with an arrow) is attributed to the absorption bands of $\mathrm{CO}_{2}$ present in the surrounding atmosphere. Figure 4 shows a significant peak at $3,500 \mathrm{~cm}^{-1}$, attributed to the surrounding $\mathrm{H}_{2} \mathrm{O}$, which was deleted in the representation of the spectra for improved reading. Above $3,000 \mathrm{~cm}^{-1}$, the low intensity of the measured signals leads to a bad signal-to-noise ratio. The spectra are nevertheless reported up to $5,500 \mathrm{~cm}^{-1}$ since they give an indication of the trend of the optical properties in this spectral range. The interpretation of the transmission spectra gives information on the penetration depth, i.e., how deep the IR radiation penetrated into the wood. For thick enough samples, the reflection spectra provide information about the amount of energy accumulated within wood: it is a measure of the efficiency of the energy transfer between the IR source and the tested material.

Both transmission and reflection increase with higher frequencies, i.e., at shorter wavelengths (Figs. 2, 3, 4, 5, 6). The amount of energy effectively absorbed by the wood is more significant at higher wavelengths than in the near-IR range next to the visible range, below $2,500 \mathrm{~cm}^{-1}$. Figure 2 shows the evolution of reflection, transmission and absorption spectra as a function of wavenumber, $1 / \lambda$, (in $\mathrm{cm}^{-1}$ ) for 1.2 and $3.1 \mathrm{~mm}$ thick green beech samples (at MCs of 60.7 and $63.6 \%$, respectively). This figure is representative of the spectra of the four species which exhibit the same behaviour for all thicknesses over $0.5 \mathrm{~mm}$. Reflection varied between 0.02 and 0.3 (i.e. between 2 and $30 \%$ ). Transmission remained weak and could be neglected. The complement to 1 of the reflection spectra gives the absorption spectra ( $\mathrm{T}$ can be omitted in Eq. 3). Absorption varied from 70 to $98 \%$ implying that as soon as the sample thickness exceeds $0.5 \mathrm{~mm}$, there is no radiation

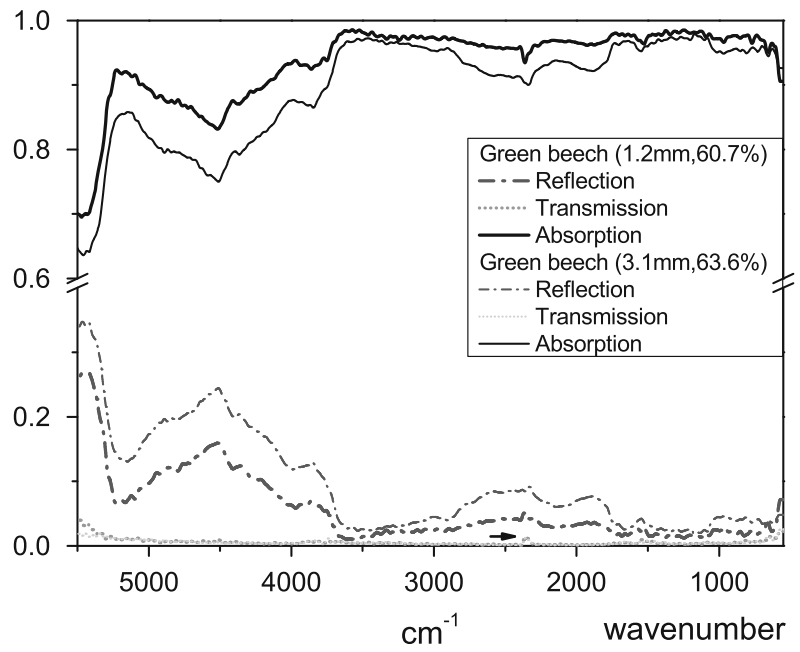

Fig. 2 Reflection, transmission and absorption spectra for 1.2 and $3.1 \mathrm{~mm}$ thick green beech samples (at 60.7 and $63.6 \% \mathrm{MC}$ ) 


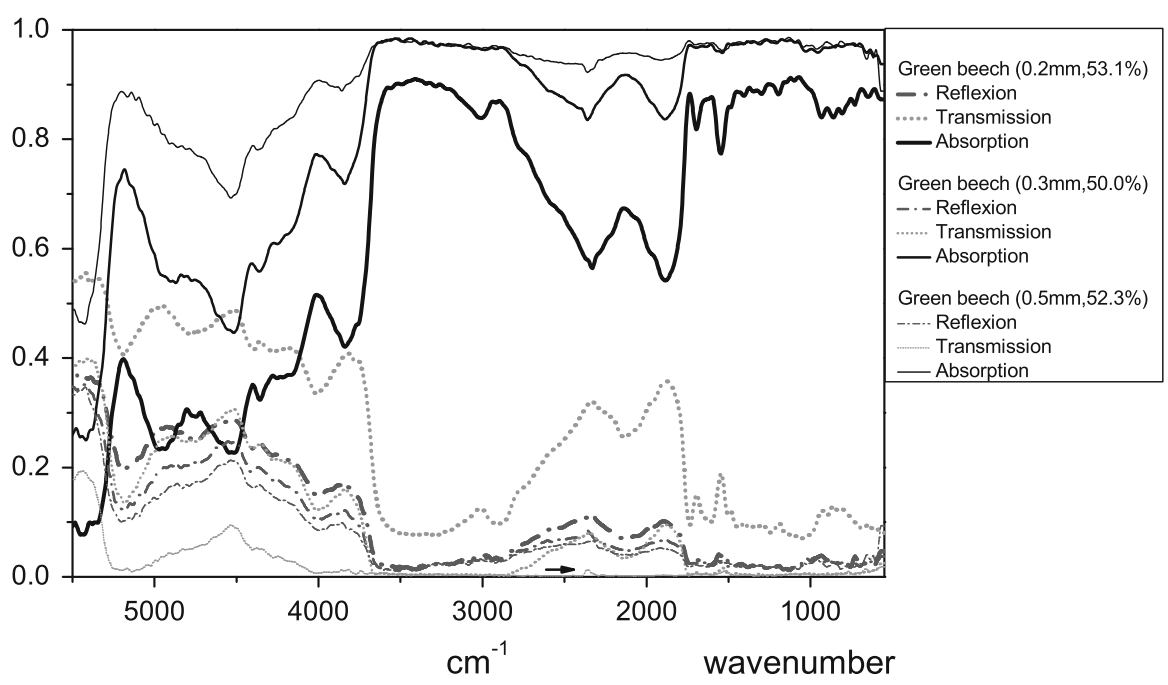

Fig. 3 Reflection, transmission and absorption spectra for $0.2,0.3$ and $0.5 \mathrm{~mm}$ thick green beech samples (at 53.1, 50.0 and $52.3 \% \mathrm{MC}$ )

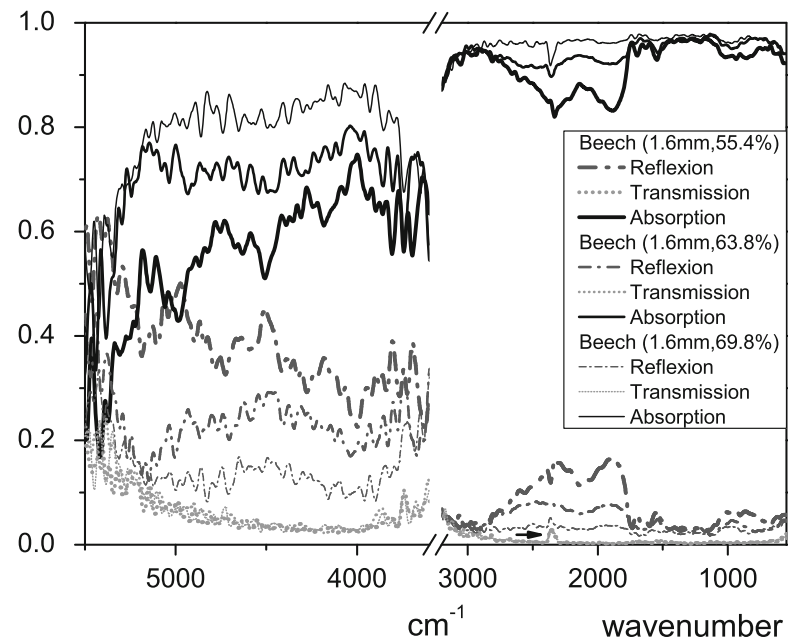

Fig. 4 Reflection, transmission and absorption spectra for $1.6 \mathrm{~mm}$ thick beech sample at 53.1, 50.0 and $52.3 \% \mathrm{MC}$

transmitted through the sample and 70-98 \% of all incident IR radiation is absorbed by the surface of the samples with no deep penetration of IR radiation within wood.

Thin (between 0.2 and $0.5 \mathrm{~mm}$ ) beech samples provided precise information about the penetration depths. Figure 3 shows the reflection, transmission and absorption spectra for green beech samples of $0.2,0.3$ and $0.5 \mathrm{~mm}$ thicknesses (at MCs of 53.1, 50.0 and $52.3 \%$, respectively). Up to $4,000 \mathrm{~cm}^{-1}$, the $0.5 \mathrm{~mm}$ sample absorbs nearly all incident energy (absorption is close to 0.95) and no energy is 


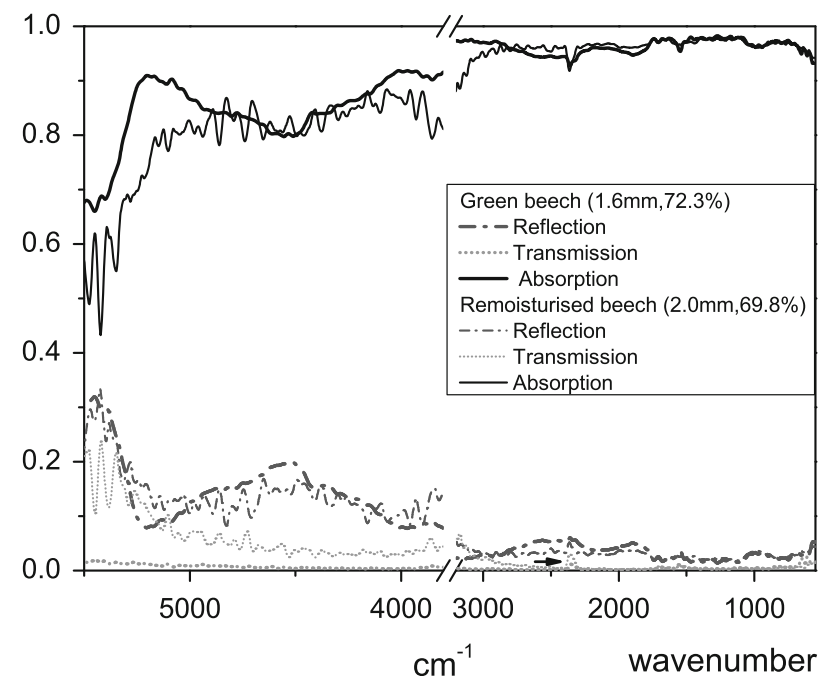

Fig. 5 Reflection, transmission and absorption spectra of green beech (1.6 mm, $72.3 \%)$ and moistened beech $(2.0 \mathrm{~mm}, 69.8 \%)$

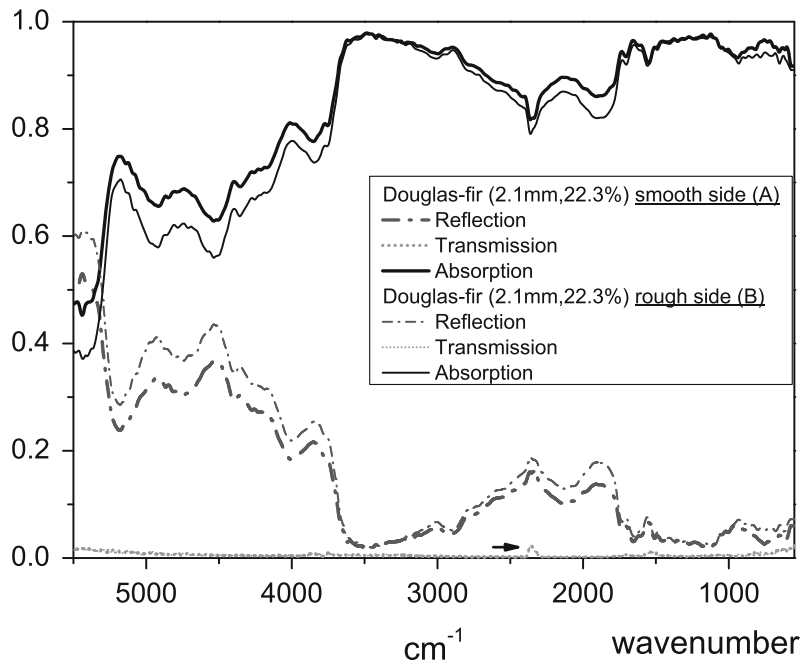

Fig. 6 Influence of the roughness on reflection, transmission and absorption spectra for a $2.1 \mathrm{~mm}$ thick green Douglas-fir sample at $22.3 \% \mathrm{MC}$ (side $B$ is rougher than side $A$ )

transmitted through the samples. In contrast, the 0.2 and $0.3 \mathrm{~mm}$ thick samples were found to transmit energy. In the $1,800-3,000 \mathrm{~cm}^{-1}$ range, transmission was found to be around 0.3 for the $0.2 \mathrm{~mm}$ thick samples and around 0.1 for the $0.3 \mathrm{~mm}$ thick samples. This indicates that between 550 and $4,000 \mathrm{~cm}^{-1}$, around $70 \%$ of the incident radiation is absorbed by the first $0.2 \mathrm{~mm}$ of wood and around $90 \%$ of the incident IR radiation in the first $0.3 \mathrm{~mm}$ of wood. The thinner the sample, the more 
radiation transmitted through it, and the thicker the sample, the greater the amount of reflected and absorbed radiation. The relatively low penetration depth of $0.3 \mathrm{~mm}$ might be explained by the heterogeneous structure of wood which can be modelled as a network of cellulose microfibrils embedded in a matrix of hemicelluloses and lignin, interspersed with water and void spaces. In the case of homogeneous materials, radiation propagates linearly with progressive exponential absorption following Beer-Lambert's law. However, the different refractive indices in heterogeneous materials backscatter the penetrating radiation preventing linear propagation, so that the strength of the radiation becomes smaller as it penetrates deeper.

Figure 4 shows the reflection, transmission and absorption spectra at different MC for $1.6 \mathrm{~mm}$ thick beech sample. All samples with thicknesses greater than $0.5 \mathrm{~mm}$ and all species tested exhibited similar behaviour. Reflection varied between 10 and $30 \%$ with the most significant amount of reflected radiation occurring on drier wood. Transmission could be neglected because it remains constantly weak (less than $5 \%$ ) without being influenced by the amount of water in wood. Therefore, $\mathrm{T}$ is negligible in Eq. 3, and the complement to 1 of reflectivity gives absorptivity. Absorption varied from 70 to $90 \%$ with the most significant amount of absorbed radiation occurring in wetter wood. The presence of water in wood is thus beneficial in terms of IR penetration because it increases the amount of absorbed energy. However, if this substantial increase serves to heat the water present in wood, it is of no interest for the purpose being investigated herein, namely to heat the wood material with IR radiation.

A further investigation was carried out on the effect of knots in wood. This issue is of concern since the characteristics of knots-for instance high density and variable grain direction (Kollmann and Côté 1968) — are known to be detrimental to veneer cutting. If knots were to absorb more energy than the surrounding wood, IR could be used, for example, to preferentially heat the knots, thereby softening them and making them easier to cut during veneer peeling. The presence of knots may be seen to increase absorption. A possible explanation for this is that the denser wood in the knots contains a relatively greater number of molecules able to absorb energy. Moreover, the different orientation of the fibres in knots may also affect energy absorption. Both wood density and fibre orientation have been noted by Zavarin et al. (1990) as factors influencing energy absorption in wood.

Figure 5 shows the spectra from the same species of wood (beech) that has either been maintained in the green state (MC of $72.3 \%$ ) or has been dried and thereafter moistened to approximately the same MC $(69.8 \%)$. As may be seen, there is no significant difference in the y-axis values between the spectra of green and moistened beech. These results are interesting in that whilst green and moistened wood are chemically the same, they are structurally slightly different materials due to the irreversible loss of hydroxyl groups during hornification: in other words, moistening wood does not liberate all hydroxyl groups 'lost' during initial drying from the green state (Suchy et al. 2009). The materials, however, interact in the same way with IR radiation. The absence of spectral differences between moistened and green wood could be explained by the state of water molecules which remains unaffected by drying and rewetting (Hoffmeyer et al. 2011). Figure 6 illustrates the 
influence of surface quality on wood absorption for a $2.1 \mathrm{~mm}$ thick green Douglasfir sample at $22.3 \%$ MC. This sample possessed different surface physical characteristics on the two sides. Side A is the tight side of the veneer and side B the loose side. Lathe checking that forms on the loose side increases veneer roughness (Dupleix et al. 2013b). From comparison of sides A and B, it may be concluded that the rougher the surface (the loose side, side B), the greater the reflection and the less absorption. This behaviour was already highlighted by Bennett and Porteus (1961) and De Santo (2007) who found that surface roughness increases light scattering and is proportional to surface reflectance. Clearly, by modifying the veneer surface quality, the peeling process influences wood absorption as also stated by Jones et al. (2008).

\section{Conclusion}

These results provided new insights into the interaction between wet wood (either green or moistened from dry) and IR radiation over the wavenumbers range from 550 to $5,500 \mathrm{~cm}^{-1}$, i.e., over wavelengths ranging from 1.8 to $18 \mu \mathrm{m}$. In general, reflection varies between 10 and $30 \%$, and the penetration depth of the radiation is close to $0.3 \mathrm{~mm}$. This means that the wood surface absorbs $70-90 \%$ of all incident IR radiation in the first $0.3 \mathrm{~mm}$ of wood, and it is not possible for energy to penetrate deeper than about $0.3 \mathrm{~mm}$. Whether penetration to this depth is sufficient to positively affect the veneer cutting stage by softening wood in the shear plane remains open for further investigation. It was also found that wood absorbs more energy at longer wavelengths, that knots increase energy absorption and that never dried green wood behaves like moistened wood. Furthermore, the roughness of the surface also influences absorption. The influence of water in wood is beneficial to IR penetration because it increases the amount of absorbed energy, but this positive effect remains limited since the energy is partly absorbed by the free water.

These findings do not necessarily suggest that the IR heating of green wood is impracticable, but they highlight the fact that IR radiation is mainly absorbed near the surface without penetrating deeply into the wood. Equations predicting the heating of wood layers beneath the surface by an external IR source should only take into account the transfer of the heat absorbed by the surface layers by conduction to the inside layers (Dupleix et al. 2013a). Future work studying temperature rise within the absorption area would contribute to a deeper understanding of the interaction between wood and IR radiation.

\section{References}

American Society for Testing and Materials (ASTM) (2002) Standard test methods for direct moisture content measurement of wood and wood-base materials. ASTM D 4442-92. In: ASTM annual book of standards. ASTM. West Conshohocken, PA

Bennett HEJ, Porteus JO (1961) Relation between surface roughness and specular reflection at normal incidence. J Opt Soc Am 51(2):123-129 
Cserta E, Hegedus G, Nemeth R (2012) Evolution of temperature and moisture profiles of wood exposed to infrared radiation. Bioresources 7(4):5304-5311

De Santo JA (2007) Overview of rough surface scattering. Light scattering and nanoscale surface roughness. Springer, Berlin, pp 211-235

Dupleix A, Ould Ahmedou SA, Bleron L, Rossi F, Hughes M (2013a) Rational production of veneer by IR-heating of green wood during peeling: modeling experiments. Holzforschung 67(1):53-58

Dupleix A, Denaud LE, Bleron L, Marchal R, Hughes M (2013b) The effect of log heating temperature on the peeling process and veneer quality: beech, birch, and spruce case studies. Eur J Wood Prod 71:163-171

Dupleix A, Kusiak A, Rossi F, Hughes M (2013c) Measuring the thermal properties of green wood by the transient plane source (TPS) technique. Holzforschung 67(4):437-445

Engelund ET, Thygesen LG, Svensson S, Hill C (2013) A critical discussion of the physics of wood-water interactions. Wood Sci Technol 47:141-161

Flir Systems ThermaCAM User's Manual (2004)

Grimhall CG, Hoel O (1983) Method of slicing veneer US Patent 4,516,614

Hoffmeyer P, Engelund ET, Thygesen LG (2011) Equilibrium moisture content (EMC) in Norway spruce during the first and second desorptions. Holzforschung 65:875-882

Jones PD, Schimleck LR, Daniels RF, Clark A, Purnell RC (2008) Comparison of Pinus taeda L. wholetree wood property calibrations using diffuse reflectance near infrared spectra obtained using a variety of sampling options. Wood Sci Technol 42(5):358-400

Kollmann FFP, Côté WA (1968) Principles of wood science. I-Solid wood. Springer, Berlin

Makoviny I, Zemiar J (2004) Heating of wood surface layers by infrared and microwave radiation. Wood Res 49(4):33-40

Marchal R, Gaudilliere C, Collet R (2004) Technical feasibility of an embedded wood heating device on the slicer or the peeling lathe. In: International symposium veneer processing and products proceedings, pp 29-44

Navi P, Sandberg D (2012) Thermo-hydro-mechanical processing of wood. EPFL Press, Lausanne, pp 159-191

Suchy M, Virtanen J, Kontturi E, Vuorinen T (2009) Impact of drying on wood ultrastructure observed by deuterium exchange and photoacoustic FT-IR spectroscopy. Biomacromolecules 11(2):515-520

Tsuchikawa S, Hayashi K, Tsutsumi S (1996) Nondestructive measurement of the subsurface structure of biological material having cellular structure by using near-infrared spectroscopy. Appl Spectrosc 50(9):1117-1124

Zavarin E, Jones SG, Cool LG (1990) Analysis of solid wood surfaces by diffuse reflectance infrared fourier-transform (DRIFT) spectroscopy. J Wood Chem Technol 10(4):495-513

Zavarin E, Cool LG, Jones SG (1991) Analysis of solid wood surfaces by internal-reflection fouriertransform infrared-spectroscopy (FTIR-IRS). J Wood Chem Technol 11(1):41-56 